\title{
Feasibility Study of Cognitive Behavioral Therapy as an Intervention for Mild Cognitive Impairment in Elderly Indonesians
}

Dharmayati Bambang Utoyo ${ }^{\mathrm{ab}}$, Retha Arjadi ${ }^{\mathrm{acd}}$, Agnes Utari Hanum Ayuningtias ${ }^{\mathrm{e}}$, and Edo S. Jaya $^{\text {ab* }}$

${ }^{a}$ Center for Ageing Studies, Universitas Indonesia, Depok, Indonesia; ${ }^{b}$ Faculty of Psychology, Universitas Indonesia, Depok, Indonesia; ${ }^{c}$ Department of Clinical Psychology and Experimental Psychopathology, University of Groningen, Groningen, The Netherlands; ${ }^{2}$ Faculty of Psychology, Atma Jaya Catholic University of Indonesia, Jakarta, Indonesia; ${ }^{e}$ Faculty of Health Sciences, Universitas Dhyana Pura, Bali, Indonesia

*Corresponding Author:

Edo S. Jaya

Psychology Research Method Department

Faculty of Psychology, Universitas Indonesia

J1. Lkr. Kampus Raya, Depok, Jawa Barat

Indonesia, 16424

Tel.: +62 217270004

Email address: edo.jaya@ui.ac.id 


\title{
Feasibility Study of Cognitive Behavioral Therapy as an Intervention for Mild Cognitive Impairment in Elderly Indonesians
}

\begin{abstract}
In Indonesia, non-medication-based methods for the treatment of elderly individuals with mild cognitive impairment (MCI) remain non-existent. This study aimed to test the feasibility of applying culturally sensitive cognitive behavioral therapy (CBT) for the treatment of elderly individuals with MCI. This study was designed as a non-randomized pre-post-test study with a control group. The participants were elderly Indonesian individuals with MCI $(\mathrm{N}=48$; treatment, $\mathrm{n}=30$; control, $\mathrm{n}=18)$. The intervention comprised six sessions of manualized CBT delivered to a group of six to seven participants over 3 weeks. Outcome measures were analyzed through analysis of covariance with pre-test scores as covariates. The results showed that by the end of the intervention period, the participants in the treatment group scored significantly better than those in the control group on the Mini Mental State Examination $(F(1,45)=6.91$, p < .05 , nation $(\mathrm{F}(1$, -word Delay Recalled Test $(\mathrm{F}(1,45)=71.22, \mathrm{p}<.01,45)=71.22$ Trailmaking Test $\mathrm{A}(\mathrm{F}(1,45)=4.21, \mathrm{p}<.05$, $\eta \mathrm{e}=0.06)$, and Memory Function Questionnaire-Frequency of Forgetting $(\mathrm{F}(1,45)=10.17, \mathrm{p}<.01, \eta \mathrm{r}=0.14)$. These promising results demonstrated that CBT can improve MCI. Although the effectiveness of the treatment remains unclear given the lack of randomization and active control group in the present study, the results are promising and warrant further investigation through randomized controlled trials.
\end{abstract}

Keywords: Mild Cognitive Impairment; Cognitive Behavioral Therapy; Indonesia; older adults

\section{Introduction}

Mild cognitive impairment (MCI) is the intermediate condition between normal cognitive decline and dementia/Alzheimer's disease (AD) (Petersen et al., 1999). MCI can be broadly categorized as amnestic and non-amnestic (Petersen, 2004). Amnestic MCI is a condition that is mainly characterized by reduced memory function and accounts for the majority of MCI cases. Nonamnestic MCI is cognitive decline that is characterized by a reduction in cognitive functions other than memory. These functions include attention, language, or visuospatial skills.

Given the importance of managing MCI, Jean and colleagues (2010) reviewed studies that focused on developing non-pharmacological intervention for patients with MCI. They found 15 studies on interventions for individuals with amnestic MCI. The reviewed interventions can be broadly categorized into cognitive training and cognitive rehabilitation (Clare \& Woods, 1996). Cognitive training involves guided practice on a set of tasks. It seeks to improve specific cognitive functions, such as memory or attention. Cognitive rehabilitation focuses on identifying and aiding individual needs and goals. This technique frequently uses compensatory methods, such as memory aids. Overall, their review showed that by the end of treatment, cognitive training and cognitive rehabilitation can significantly improve the parameters of memory function (Jean et al., 2010).

However, to our knowledge, no MCI treatment that targets the behavioral, affective, and cognitive risk factors of MCI has been developed. For example, moderate exercise decreases the risk of MCI (Geda et al., 2010), whereas depression increases the risk of MCI (Geda et al., 2006; 
Modrego \& Ferrández, 2004). Indeed, elderly adults with MCI and depression are twice as likely to develop dementia than those without depression (Modrego \& Ferrández, 2004). Furthermore, the absence of cognitively stimulating activities in a natural setting increases the risk of MCI (Hultsch, Hertzog, Small, \& Dixon, 1999). This risk has been further validated in a large scale study by Hall and colleagues (2009). Modifying the risk factors of MCI fit well into the framework of cognitive behavioral therapy (CBT), a psychological treatment principle that specifically aims to change the behavioral, affective, and cognitive aspects of the client (Beck, 1995).

We hypothesized that the regular performance of cognitive stimulating activities based on CBT principles in a natural environment will reduce MCI symptoms. In contrast to cognitive training treatment that provides cognitive stimulation in a controlled artificial environment created by the therapist, our approach is performed in a natural environment. Thus, our treatment may be sustainable and keep the participants cognitively stimulated even after the end of the treatment.

However, no CBT-based treatment has been developed for CMI, and CBT-based treatments have not been tested in an Indonesian context. Therefore, we developed a manual for a CBT-based treatment that is sensitive to the Indonesian cultural context. The treatment was then delivered in a group setting by licensed clinical psychologists. The effectiveness of the treatment, termed CBT for MCI, in reducing MCI symptoms was investigated with a quasi-experimental, nonrandomized, pre-test-post-test control group design. The analysis was conducted by comparing the post-test scores of the outcome measures of the experimental and control groups with the pretest score as a covariant.

\section{Methods}

\section{Research Design}

This study has a non-randomized, pre-test post-test, control group experimental design (Kerlinger \& Lee, 2000). This study was approved by the Ethical Committee of Faculty of Psychology, University of Indonesia, Indonesia. Written informed consent was obtained from the participants of the experimental and control groups.

\section{Procedures}

Participants were recruited by announcing the research at several activity centers for the elderly in Depok, West Java, Indonesia. The researchers and research assistants gave out initial screening questionnaires to individuals who have experienced subjective cognitive decline and expressed interest in participating in the research. A total of 176 participants completed the initial screening questionnaire and agreed to be contacted by phone for further participation in the research. All of the respondents were contacted by phone to participate in the pre-test session, and 53 participants were willing to participate. However, only 30 respondents attended the pre-test session, and all of these respondents were assigned to the experimental group. The other participants who did not attend $(\mathrm{N}=23)$ the session were contacted again, and they reported that they were unable to participate in the pre-session because they had difficulty traveling to the session as a result of various reasons (e.g., have a grandchildren at home). Then, we offered to deliver the treatment at the respondent's place of residence if they filled in the questionnaires twice in exchange (baseline and the 3 weeks post-test). Some respondents agreed, and this group of participants became the 
waiting list control group $(\mathrm{N}=18)$. Following the treatment manual, the treatment was delivered by licensed clinical psychologists (RA and SJK) in group format.

\section{Diagnosis}

MCI was diagnosed on the basis of the diagnosis flowchart established by Petersen (2004, p. 200). First, individuals who have subjective cognitive complaints were asked to participate. Then, a clinical psychologist (RA) briefly assessed the respondents for symptoms of dementia or AD. None of the volunteers qualified for dementia or AD given their normal functional activities. This result was expected because we were using sport activity locations as our recruitment sites. After ruling out participants with dementia or $\mathrm{AD}$, we attempted to rule out participants without symptoms of objective cognitive decline. Following the guidelines set by Petersen (2004, p. 200), we assumed that participants with a pre-test Mini Mental States Examination (MMSE) score of 29 and 30 can be categorized as normal and were thus excluded from the experiment.

\section{Measures}

Treatment efficacy was measured using four main outcome measures: MMSE, 10-word Delayed Recall Test (WDRT), Trail-making Tests (TMT) A and B, and Memory Functioning Questionnaire (MFQ)-Frequency of Forgetting scale. Additionally, Client Satisfaction Questionnaire-8 (CSQ-8) was used to measure client satisfaction. Except for CSQ-8, which has been previously used in an Indonesian study (Utoyo et al., 2013), most of these measures are unavailable in Bahasa and had to be back-translated by the authors,.

\section{MMSE}

MMSE was originally developed to differentiate the cognitive ability of patients with dementia from that of patients with other psychological disorders, such as affective disorders and schizophrenia (Folstein, Folstein, \& McHugh, 1975). It has become one of the most commonly used measures for cognitive decline associated with psychological disorders, such as dementia and AD (Mitchell, 2009). This measure consists of several items representing several areas of cognitive functions: orientation, registration (or immediate recall), attention, calculation, recall (or delayed recall), and language and praxis. MMSE is an interview-based measure. In this measure, the reviewers must ask questions, as well as score the answers of the participants following a guideline.

Clinical psychologists in training administered the MMSE with supervision from a licensed clinical psychologist (RA). The original measure was back-translated by the authors and modified to account for the Indonesian context following the principle of the original test. The modification focused on the orientation and repetition items under language and praxis. The orientation item asking about season is inappropriate for the Indonesian context because Indonesia has a tropical climate, not seasons. Thus, this item was replaced with a question on the time of the day (morning, noon, and night) and another question involving work days or weekend. Moreover, the items under location were changed into countries, province, city, regency, current location (e.g., sport field, house), and building level. Furthermore, the repetition item under language and praxis was changed from "no ifs, ands, or buts" into a familiar Indonesian colloquialism: "consciousness leads to intelligence" ("rajin pangkal pandai"). The maximum score of the modified MMSE used is 32 .

\section{0-WDRT}

Numerous variations of the 10-WDRT exist. In this study, the participants were given a piece of paper with instructions and 10 words. They were asked to memorize the words without writing 
them down. After $1 \mathrm{~min}$, the participants were asked to perform other activities, such as an ice breaking game, or converse with the researchers or other participants. After $20 \mathrm{~min}$ had passed, the participants were asked to recall the 10 words and write them in a given answering sheet. The 10-WDRT can discriminate among MCI, AD, or signs of normal aging (Takayama, 2010). A 10year longitudinal study in Japan has shown that the measure can differentiate between individuals with or without MCI on the basis of the score of $6 / 7$ (sensitivity $93.1 \%$ and specificity $90.3 \%$ ), or between individuals with or without AD on the basis of the score of $4 / 5$ (sensitivity $100 \%$ and specificity $100 \%$ ).

\section{3-item MFQ-Frequency of Forgetting Scale}

The MFQ is a self-reporting questionnaire that was developed to measure memory complaints among adults and older adults (Gilewski \& Zelinski, 1988; Gilewski, Zelinski, \& Schaie, 1990). It consists of three dimensions that comprise 64 items, which include frequency of forgetting, severity of forgetting, retrospective function, and mnemonic usage. Every item is answered with a 7-point Likert scale.

In this study, however, only the frequency of forgetting subscale was used. This consists of 33 items and measures the frequency of forgetting over several components, such as everyday life, reading a novel, remembering events, and reading a newspaper or magazine article. An example item on everyday life is "How often do these present a problem for you? Names, faces, appointments, and others." The participant may provide the following answers, Always (1 and 2), Sometimes (3-5), and Never (6-7).

\section{TMT A and B}

The TMT was originally conceptualized to reveal the presence of organic brain damage in hospital patients (Reitan, 1958). However, researchers have found that TMT A and B measure some items differently and may provide specific cognitive measures. TMT A can used as an indicator of visuoperceptual tasks, and TMT B as a measure of working memory and attention (Sánchez-Cubillo et al., 2009).

Despite their different functions, TMT A and B appear similar and are scored similarly. For TMT A, participants were asked to draw a line to connect numbers continually from 1 to 25 . For TMT, B participants were asked to connect numbers to letters, then back to numbers again (for example: A-1-B-2-C-3). Participants were asked to finish the test as accurately as possible, and the time taken to finish the task was counted in seconds.

\section{CSQ-8}

The CSQ-8 is used to measure the satisfaction of the participants with the provided treatment (Attkisson \& Zwick, 1982; Larsen, Attkisson, Hargreaves, \& Nguyen, 1979). The CSQ-8 is short and easily understood. The measure consists of eight items scored on a 4-point Likert scale and has a total score of 8 to 32. This questionnaire has been previously used to investigate the effect of group CBT in Indonesia (Utoyo et al., 2013).

\section{Treatment: Group CBT for MCI}

The treatment consisted of six 90 min sessions and was delivered over 3 weeks with two sessions per week. Each session was separated by 3 to 4 days. Licensed clinical psychologists (RA and SJK) delivered the treatment to a group of six to seven participants. The delivery of the treatment followed a schedule and used the techniques described in the treatment manual. From the third session onward, every session started with relaxation therapy. 
The first session provided psychoeducation on MCI. The first session was provided to inform the participants about MCI and to initiate a discussion about the effects of MCI on daily life with an emphasis on daily social life. The second session involved teaching the participants several relaxation techniques, including breathing relaxation, progressive muscular relaxation, and imagery relaxation. The participants were encouraged to practice the techniques at home and to record their practice by completing an activity worksheet. The third session involved a discussion of the participants' daily activities. In this session, the therapists discussed daily activities that the participants can perform to keep them active. During the fourth session, the therapists delivered materials on cognitive technique. The aim of the fourth session was to teach the participants to view things from a different perspective and was delivered in the context of Indonesian culture. For example, the opinion that traveling and performing enjoyable activities are only for young people and are inappropriate for the elderly is prevalent among elderly Indonesian individuals. This was discussed as an example of a not useful perspective of aging. The fifth session delivered materials on problem solving techniques. Finally, the sixth session provided a review of all the techniques that have been delivered and their effectiveness.

\section{Analysis}

Analysis of covariance was used to examine the treatment effect. Specifically, we used the pretest as a covariant when comparing the post-test scores of the experimental and control groups. This method of analysis is recommended over the normally used repeated measure ANOVA for the pre-test post-test control group experimental design (Dimitrov \& Rumrill, 2003; Huck \& McLean, 1975). Bonferonni correction was performed to adjust confidence intervals.

\section{Results}

\section{Participant Characteristics}

A total of 48 elderly individuals participated in this study. The experimental groups comprised 30 participants, and the control group comprised 18 participants. The average age of the participants was 65.02 years old $(\mathrm{SD}=7.10)$. Most of the participants were female $(\mathrm{N}=30,62.5 \%)$. However, the participants' gender in the experimental group was quite equal at 13 males and 17 females. Most of the participants were married (66.7\%), had received university education (50\%), on pension (45.8\%), and had a monthly expenditure of 1 million to 3.5 million Rupiah, or approximately US\$90 to US\$310. Refer to Table 1 for details.

Table 1

Participant Characteristics

\begin{tabular}{lccc}
\hline & Experimental group (N=30) & Control group (N=18) & Total (N=48) \\
\hline Age & $66.40(\mathrm{SD}=7.24)$ & $62.72(\mathrm{SD}=6.41)$ & $65.02(\mathrm{SD}=7.10)$ \\
Gender & & & $18(37.5 \%)$ \\
Male & $13(43.3 \%)$ & $5(27.8 \%)$ & $30(62.5 \%)$ \\
Female & $17(56.7 \%)$ & $13(72.2 \%)$ & $2(4.2 \%)$ \\
Marriage status & $1(3.3 \%)$ & $1(5.6 \%)$ & $32(66.7 \%)$ \\
Single & $22(73.3 \%)$ & $10(55.6 \%)$ & $12(25.0 \%)$ \\
Married & $6(20.0 \%)$ & $6(33.3 \%)$ & $2(4.2 \%)$ \\
Widowed & $1(3.3 \%)$ & $1(5.6 \%)$ & $2(4.2 \%)$ \\
Divorced & & & $7(14.6 \%)$ \\
Education & $1(0 \%)$ & $2(11.1 \%)$ & $15(31.3 \%)$ \\
Primary school (Year 1-6) & $12.3 \%)$ & $6(33.3 \%)$ & $24(50.0 \%)$ \\
Junior high school (Year 7-9) & $17(56.7 \%)$ & $3(16.7 \%)$ & $7(38.9 \%)$ \\
Senior high school (Year10-12) & & & \\
University & & & \\
\hline
\end{tabular}


Table 1, cont.

Participant Characteristics

\begin{tabular}{lccc}
\hline & Experimental group $(\mathrm{N}=30)$ & Control group $(\mathrm{N}=18)$ & Total $(\mathrm{N}=48)$ \\
\hline $\begin{array}{l}\text { Monthly expenditure } \\
\text { Rp 500,000-1,000,000 }\end{array}$ & $4(13.3 \%)$ & $1(5.6 \%)$ & $5(10.4 \%)$ \\
$\begin{array}{l}\text { (equiv. } \pm \text { US } \$ 44- \pm \text { US } \$ 88) \\
\text { Rp 1,000,001-Rp 3,500,000 }\end{array}$ & $18(60.0 \%)$ & $13(72.2 \%)$ & $31(64.6 \%)$ \\
$\begin{array}{l}\text { Rp 3,500,001-Rp6,000,000 } \\
\text { (equiv. } \pm \text { US } \$ 308- \pm \text { US } \$ 528)\end{array}$ & $5(16.7 \%)$ & $4(22.2 \%)$ & $9(18.8 \%)$ \\
$\begin{array}{l}\text { Above Rp 6,000,000 } \\
\text { (equiv. above } \pm \text { US\$ 528) }\end{array}$ & $3(10 \%)$ & $0(0 \%)$ & $3(6.3 \%)$ \\
\hline
\end{tabular}

\section{Treatment vs. Control Group}

The treatment and control groups had significantly different outcome measures. The MMSE ( $F$ $(1,45)=6.91, p<.05, \eta 2=0.11), 10 \operatorname{WDRT}(F(1,45)=71.22, p<.01, \eta 2=0.52)$, TMT A $(F$ $(1,45)=4.21, p<.05, \eta 2=0.06)$, and MFQ-Frequency of Forgetting Scale $(F(1,45)=10.17, p$ $<.01, \eta 2=0.14)$ of the two groups were significantly different. However, the TMT B measure $(F$ $(1,45)=1.60, p>.05, \eta 2=0.02)$ of the two groups were not significantly different. Refer to Table 2 for the detailed descriptive statistics of the outcome measures.

Table 2

Results of Outcome Measures

\begin{tabular}{|c|c|c|c|c|}
\hline & Treatment group $(\mathrm{N}=30)$ & Control group $(\mathrm{N}=18)$ & $\mathrm{F}$ & Effect size $(\eta 2)$ \\
\hline MMSE & & & $6.91 *$ & 0.11 \\
\hline Pre-Test & $29.23(\mathrm{SD}=2.18)$ & $30.28(\mathrm{SD}=1.81)$ & & \\
\hline Post-Test & $30.77(\mathrm{SD}=1.00)$ & $29.94(\mathrm{SD}=2.29)$ & & \\
\hline $10 \mathrm{WDRT}$ & & & $71.22 * *$ & 0.61 \\
\hline Pre-Test & $5.70(\mathrm{SD}=3.15)$ & $4.56(\mathrm{SD}=1.89)$ & & \\
\hline Post-Test & $8.43(\mathrm{SD}=1.98)$ & $3.83(\mathrm{SD}=1.82)$ & & \\
\hline TMT A & & & $4.21 *$ & 0.09 \\
\hline Pre-Test & $94.37(\mathrm{SD}=44.82)$ & $78.11(\mathrm{SD}=23.54)$ & & \\
\hline Post-Test & $69.20(\mathrm{SD}=32.00)$ & $77.33(\mathrm{SD}=23.51)$ & & \\
\hline TMT B & & & 1.60 & 0.03 \\
\hline Pre-Test & $204.23(\mathrm{SD}=99.44)$ & $177.44(\mathrm{SD}=28.79)$ & & \\
\hline Post-Test & $163.00(\mathrm{SD}=68.64)$ & $171.67(\mathrm{SD}=47.73)$ & & \\
\hline MFQ & & & $10.18^{* *}$ & 0.18 \\
\hline Pre-Test & $147.60(\mathrm{SD}=22.92)$ & $140.39(\mathrm{SD}=13.31)$ & & \\
\hline Post-Test & $154.87(\mathrm{SD}=17.21)$ & $139.06(\mathrm{SD}=12.08)$ & & \\
\hline
\end{tabular}

Additionally, the CSQ-8 measure showed that the participants are generally satisfied with the treatment. A total of 48 participants from the treatment and control group responded to the satisfaction questionnaire. The average score was $3.19(\mathrm{SD}=0.50)$ and was close to the third point of the scale, which is "satisfied."

\section{Discussion}

The overall results supported the hypothesis that CBT for MCI attenuated the severity of MCI symptoms in elderly Indonesian individuals, as indicated by the statistically significant post-test scores of the experimental and control groups after controlling the pre-test scores for most outcome measures. The differences in effect size and statistical significance between the four outcome measures supported the notion that the treatment is particularly effective for decreasing the symptoms of amnestic MCI, i.e., forgetfulness. However, the treatment is not highly effective 
in treating symptoms of non-amnestic MCI, specifically symptoms that involve other cognitive functions, such as attention. This interpretation is supported by the different results of the experimental and control groups for 10-WDRT and MFQ, which are both are specific measures of memory.

Most importantly, this study showed that behavioral and cognitive changes may reduce MCI symptoms. Thus, the results of this study may provide some of the limited available evidence showing that engagement in cognitively stimulating activities may reduce the severity of MCI symptoms and are in line with the conclusion drawn Wilson and colleagues (2002). Wilson and colleagues retrospectively showed that engaging in cognitively stimulating activities reduces the risk of AD. Moreover, the efficacy of the treatment supports the view that treating the emotional condition of the participants is an important step in attenuating the intensity of MCI symptoms. In this study, participants were taught relaxation, cognitive, and problem-solving techniques specifically to decrease the severity of MCI symptoms.

To the best of our knowledge, this study is the first to modify and apply CBT techniques to treat MCI. Furthermore, this is also the first study that tested a non-pharmacological treatment approach for MCI in elderly Indonesian individuals. Given the novelty of our study, we are unsure whether we should investigate this topic through a randomized controlled trial (RCT), the golden standard of treatment testing. This design limitation complicated deriving inferences about the effectiveness of the present treatment. Future research should replicate the applied treatment in a study with a RCT design. Nevertheless, this study provides the first evidence that $\mathrm{CBT}$ is a feasible treatment strategy for reducing MCI symptoms.

\section{Acknowledgment}

We are grateful to Sri Juwita Kusumawardhani (SJK) for delivering the treatment. We are also thankful to Erwin Suhirdjo for providing access for the data gathering process from Perhimpunan Gerontologi Indonesia (PERGERI) in Depok, West Java, Indonesia. This study was funded by Directorate of Research and Community Engagement, University of Indonesia under the program of Intermediate Research Grant (2012). The funding source was not involved with the conduct of the research and preparation of the article.

\section{References}

Attkisson, C. C., \& Zwick, R. (1982). The client satisfaction questionnaire: Psychometric properties and correlations with service utilization and psychotherapy outcome. Evaluation and Program Planning, 5(3), 233-237. https://doi.org/10.1016/01497189(82)90074-X

Beck, J. S. (1995). Cognitive Therapy: Basics and Beyond. Guilford Press.

Clare, L., \& Woods, B. (1996). Cognitive rehabilitation and cognitive training for early-stage Alzheimer's disease and vascular dementia. In Cochrane Database of Systematic Reviews. John Wiley \& Sons, Ltd. Retrieved from http://onlinelibrary.wiley.com/doi/10.1002/14651858.CD003260/abstract

Dimitrov, D. M., \& Rumrill, J. (2003). Pretest-posttest designs and measurement of change. Work: A Journal of Prevention, Assessment and Rehabilitation, 20(2), 159-165.

Folstein, M. F., Folstein, S. E., \& McHugh, P. R. (1975). "Mini-mental state": A practical method for grading the cognitive state of patients for the clinician. Journal of Psychiatric Research, 12(3), 189-198. https://doi.org/10.1016/00223956(75)90026-6

Geda, Y. E., Knopman, D. S., Mrazek, D. A., Jicha, G. A., Smith, G. E., Negash, S., ... Rocca, W. A. (2006). Depression, apolipoprotein E genotype, and the incidence of mild cognitive impairment: a prospective cohort study. Archives of Neurology, 63(3), 435-440. https://doi.org/10.1001/archneur.63.3.435 
Geda, Y. E., Roberts, R. O., Knopman, D. S., Christianson, T. J. H., Pankratz, V. S., Ivnik, R. J., ... Rocca, W. A. (2010). Physical exercise, aging, and mild cognitive impairment: a population-based study. Archives of Neurology, 67(1), 80-86. https://doi.org/10.1001/archneurol.2009.297

Gilewski, M. J., \& Zelinski, E. M. (1988). Memory Functioning Questionnaire (MFQ). Psychopharmacology Bulletin, 24(4), 665-670.

Gilewski, M. J., Zelinski, E. M., \& Schaie, K. W. (1990). The Memory Functioning Questionnaire for assessment of memory complaints in adulthood and old age. Psychology and Aging, 5(4), 482-490.

Hall, C. B., Lipton, R. B., Sliwinski, M., Katz, M. J., Derby, C. A., \& Verghese, J. (2009). Cognitive activities delay onset of memory decline in persons who develop dementia. Neurology, 73(5), $356-361$. https://doi.org/10.1212/WNL.0b013e3181b04ae3

Huck, S. W., \& McLean, R. A. (1975). Using a repeated measures ANOVA to analyze the data from a pretest-posttest design: A potentially confusing task. Psychological Bulletin, 82(4), 511-518. https://doi.org/10.1037/h0076767

Hultsch, D. F., Hertzog, C., Small, B. J., \& Dixon, R. A. (1999). Use it or lose it: Engaged lifestyle as a buffer of cognitive decline in aging? Psychology and Aging, 14(2), 245-263. https://doi.org/10.1037/0882-7974.14.2.245

Jean, L., Bergeron, M.-E., Thivierge, S., \& Simard, M. (2010). Cognitive intervention programs for individuals with mild cognitive impairment: systematic review of the literature. The American Journal of Geriatric Psychiatry: Official Journal of the American Association for Geriatric Psychiatry, 18(4), 281-296. https://doi.org/10.1097/JGP.0b013e3181c37ce9

Kerlinger, F. N., \& Lee, H. B. (2000). Foundations of behavioral research. San Diego: Harcourt College Publishers.

Larsen, D. L., Attkisson, C. C., Hargreaves, W. A., \& Nguyen, T. D. (1979). Assessment of client/patient satisfaction: Development of a general scale. Evaluation and Program Planning, 2(3), 197-207. https://doi.org/10.1016/01497189(79)90094-6

Mitchell, A. J. (2009). A meta-analysis of the accuracy of the mini-mental state examination in the detection of dementia and mild cognitive impairment. Journal of Psychiatric Research, 43(4), 411-431. https://doi.org/10.1016/j.jpsychires.2008.04.014

Modrego, P. J., \& Ferrández, J. (2004). Depression in patients with mild cognitive impairment increases the risk of developing dementia of alzheimer type: A prospective cohort study. Archives of Neurology, 61(8), 1290-1293. https://doi.org/10.1001/archneur.61.8.1290

Petersen, R. C. (2004). Mild cognitive impairment as a diagnostic entity. Journal of Internal Medicine, $256(3), 183-194$. https://doi.org/10.1111/j.1365-2796.2004.01388.x

Petersen, R. C., Smith, G. E., Waring, S. C., Ivnik, R. J., Tangalos, E. G., \& Kokmen, E. (1999). Mild cognitive impairment: clinical characterization and outcome. Archives of Neurology, 56(3), 303-308.

Reitan, R. M. (1958). Validity of the Trail Making Test as an indicator of organic brain damage. Perceptual and Motor Skills, 8, 271-276. https://doi.org/10.2466/PMS.8.7.271-276

Sánchez-Cubillo, I., Periáñez, J. A., Adrover-Roig, D., Rodríguez-Sánchez, J. M., Ríos-Lago, M., Tirapu, J., \& Barceló, F. (2009). Construct validity of the Trail Making Test: role of task-switching, working memory, inhibition/interference control, and visuomotor abilities. Journal of the International Neuropsychological Society: JINS, 15(3), 438-450. https://doi.org/10.1017/S1355617709090626

Takayama, Y. (2010). A delayed recall battery as a sensitive screening for mild cognitive impairment: follow-up study of memory clinic patients after 10 years. Journal of Medical and Dental Sciences, 57(2), 177-184.

Utoyo, D. B., Jaya, E. S., Arjadi, R., Hanum, L., Astri, K., \& Putri, M. D. D. (2013). Preliminary study on the effectiveness of short group cognitive behavioral therapy (GCBT) on Indonesian older adults. PLoS ONE, 8(2), e57198. https://doi.org/10.1371/journal.pone.0057198

Wilson, R. S., Mendes De Leon, C. F., Barnes, L. L., Schneider, J. A., Bienias, J. L., Evans, D. A., \& Bennett, D. A. (2002). Participation in cognitively stimulating activities and risk of incident Alzheimer disease. JAMA: The Journal of the American Medical Association, 287(6), 742-748. 